\title{
Proteolytic biomarkers are related to prognosis in COPD- report from a population-based cohort
}

\author{
Robert Linder $^{1 *}$ D, Eva Rönmark ${ }^{2}$, Jamshid Pourazar ${ }^{1}$, Annelie F. Behndig $^{1}$, Anders Blomberg ${ }^{1}$ and Anne Lindberg ${ }^{1}$
}

\begin{abstract}
Background: The imbalance between proteases and anti-proteases is considered to contribute to the development of COPD. Our aim was to evaluate the protease MMP-9, the antiprotease TIMP-1 and the MMP-9/TIMP-1-ratio as biomarkers in relation to prognosis. Prognosis was assessed as lung function decline and mortality. This was done among subjects with COPD in a population-based cohort.

Methods: In 2005, clinical examinations including spirometry and peripheral blood sampling, were made in a longitudinal population-based cohort. In total, 1542 individuals participated, whereof 594 with COPD. In 2010, 1031 subjects participated in clinical examinations, and 952 subjects underwent spirometry in both 2005 and 2010. Serum MMP-9 and TIMP-1 concentrations were measured with enzyme linked immunosorbent assay (ELISA). Mortality data were collected from the Swedish national mortality register from the date of examination in 2005 until 31st December 2010.
\end{abstract}

Results: The correlation between biomarkers and lung function decline was similar in non-COPD and COPD, but only significant for MMP-9 and MMP-9/TIMP-1-ratio in non-COPD. Mortality was higher in COPD than non-COPD (16\% vs. $10 \%, p=0.008)$. MMP-9 concentrations and MMP-9/TIMP-1 ratios in 2005 were higher among those who died during follow up, as well as among those alive but not participating in 2010, when compared to those participating in the 2010-examination. In non-COPD, male sex, age, burden of smoking, heart disease and MMP-9/TIMP-1 ratio were associated with increased risk for death, while increased TIMP-1 was protective. Among those with COPD, age, current smoking, increased MMP-9 and MMP-9/TIMP-1 ratio were associated with an increased risk for death.

Conclusions: The expected association between these biomarkers and lung function decline in COPD was not confirmed in this population-based study, probably due to a healthy survivor effect. Still, it is suggested that increased proteolytic imbalance may be of greater prognostic importance in COPD than in non-COPD.

Keywords: Chronic obstructive pulmonary disease (COPD), Matrix metalloproteinases, Tissue inhibitor of metalloproteinases, Mortality, Spirometry

\section{Background}

Chronic obstructive pulmonary disease, COPD, is today considered a heterogeneous syndrome, including several clinical phenotypes [1]. Under-diagnosis is common; around $20-30 \%$ of all cases are identified by healthcare. Most of the current knowledge regarding the pathophysiological mechanisms in COPD is based on highly

\footnotetext{
* Correspondence: robert.linder@umu.se

${ }^{1}$ Department of Public Health and Clinical Medicine, Division of Medicine,

Umeå University, SE-90187 Umeå, Sweden

Full list of author information is available at the end of the article
}

selected study populations [2,3]. Thus, it is unclear to what extent the results are generalisable to COPD in the population.

The discovery of alpha-1-antitrypsin deficiency (AATD) and its association with emphysema in smokers provided the concept of imbalance between proteases and antiproteases and its contribution to COPD development [4]. Cross-sectional studies on selected COPD-populations have observed increased levels of matrix metalloproteinase-9 (MMP-9) in COPD, and an association between the level of MMP-9 and $\mathrm{FEV}_{1}$ [5-7]. We have recently shown an

(C) The Author(s). 2018 Open Access This article is distributed under the terms of the Creative Commons Attribution 4.0 International License (http://creativecommons.org/licenses/by/4.0/), which permits unrestricted use, distribution, and 
inverse relationship between $\mathrm{FEV}_{1}$ and serum MMP-9 in a cross-sectional study of a population-based COPD-cohort [8]. This indicates that increased proteolytic activity is associated with disease severity not only in selected COPD populations. However, MMP-9 should be considered in relation to the tissue inhibitor of metalloproteinases-1 (TIMP-1), because of its inhibiting effect on MMP-9 $[6,9]$.

There are a few longitudinal studies within this topic, of small and selected study populations. These studies indicate that MMP-9 is related to lung function decline in COPD [10]. Also, in a selected population of patients with AATD-associated emphysema, higher plasma MMP-9 levels were associated with disease progression [11]. Still, the link between proteolytic imbalance and long-term COPD disease progress has not yet been evaluated in population-based studies. We believe that our population-based COPD cohort provides an excellent basis for a longitudinal follow-up, when it comes to addressing the prognostic value of MMP-9 in COPD [8].

The first aim of this population-based study was to evaluate the biomarkers MMP-9, TIMP-1 and MMP-9/ TIMP-1 ratio in serum. The second aim was to put this in relation to disease progress and prognosis, assessed as lung function decline and mortality respectively. The third aim was to do this among subjects with and without COPD.

\section{Methods}

\section{Participants and design}

The Obstructive Lung Disease in Northern Sweden (OLIN) COPD study includes all 993 subjects with COPD (defined as $\mathrm{FEV}_{1} / \mathrm{VC}<0.7$ ) together with 993 age and sex-matched controls without obstructive lung function impairment identified during reexamination of population-based cohorts in 2002-04. The study population $(n=1986)$ has since 2005 been annually invited to a basic examination program. The current study population includes all 1542 subjects with complete data on structured interview, spirometry and blood sampling participating in the 2005examinations. Study design, recruitment of study population, participation and basic characteristics in 2005 , are previously described in detail $[8,12]$.

Follow-up spirometry data were collected from the 2010-examinations of the cohort under study. All-cause mortality data were collected from the Swedish national mortality register from the date of examination in 2005 until end of December 2010. In 2010, 1379 out of the 1542 were still alive, and 1031 of them participated in clinical examination. In total 952 subjects participated in the clinical examinations, including spirometry, in both 2005 and 2010 (Fig. 1). The Regional Ethics Committee at Umeå University approved the study, which was carried out according to the declaration of Helsinki. All participants provided written informed consent before the performance of any study-related assessments.

\section{Structured interview questionnaire}

Previously validated questions regarding respiratory symptoms were used in a structured interview [13-15]. In addition, data on smoking habits and co-morbidities, such as heart disease (defined as one or more of either; angina pectoris, myocardial infarction, coronary artery bypass graft (CABG) surgery, percutaneous coronary intervention (PCI) and chronic heart failure), were included.

\section{Spirometry; spirometric classification and definitions of decline in lung function}

A Mijnhardt Vicatest 5 dry spirometer was used to obtain lung function data, following the ATS guidelines of procedure [16]. A reversibility test was carried out if $\mathrm{FEV}_{1}$ / highest of FVC or SVC $<0.70$, or if $\mathrm{FEV}_{1}<80 \%$ of predicted value. COPD was defined as $\mathrm{FEV}_{1}$ divided by $\mathrm{FVC}$ or SVC $<0.70$, using the highest values pre- or postbronchodilation. Disease severity was classified according to the GOLD (Global Initiative for Obstructive Lung Disease) spirometric criteria based on $\mathrm{FEV}_{1} \%$ predicted; GOLD 1-4 [17]. Local reference values were used for $\mathrm{FEV}_{1}[18]$.

Lung function change from 2005 until 2010, assessed as change of $F E V_{1}$ using the highest value of $\mathrm{FEV}_{1}$ either pre- or post-bronchodilation, was calculated as:

1) The mean $\mathrm{FEV}_{1}$ decline (ml/year); the unadjusted difference in $\mathrm{FEV}_{1}$ in $\mathrm{ml}$ (absolute value of $\mathrm{FEV}_{1}$ 2010 - absolute value of $\mathrm{FEV}_{1} 2005$ divided by number of years of observation time, based on person days).

2) Annual change in units of percent predicted normal value of $\mathrm{FEV}_{1}$. $\left(\mathrm{FEV}_{1} \%\right.$ predicted $2010-\mathrm{FEV}_{1} \%$ predicted 2005 divided by number of years of observation time, based on person days) [19].

\section{Laboratory analysis}

The handling and analyses of blood samples have been described previously [8]. Samples were stored since 2005 at $-20{ }^{\circ} \mathrm{C}$, thereafter thawed and analysed simultaneously in 2013. Serum concentrations of MMP-9 and TIMP-1 were assayed using commercially available ELISA kits (DuoSet ${ }^{\circ}$ ELISA Development System, R\&D Systems Europe Ltd., United Kingdom), according to the manufacturer's instructions.

\section{Statistical analysis}

Dichotomous variables were analysed using Pearson's $\chi^{2}$ and continuous variables with the Mann-Whitney U-test since they did not meet the criterion of normal distribution. Non-normally distributed data are presented as 


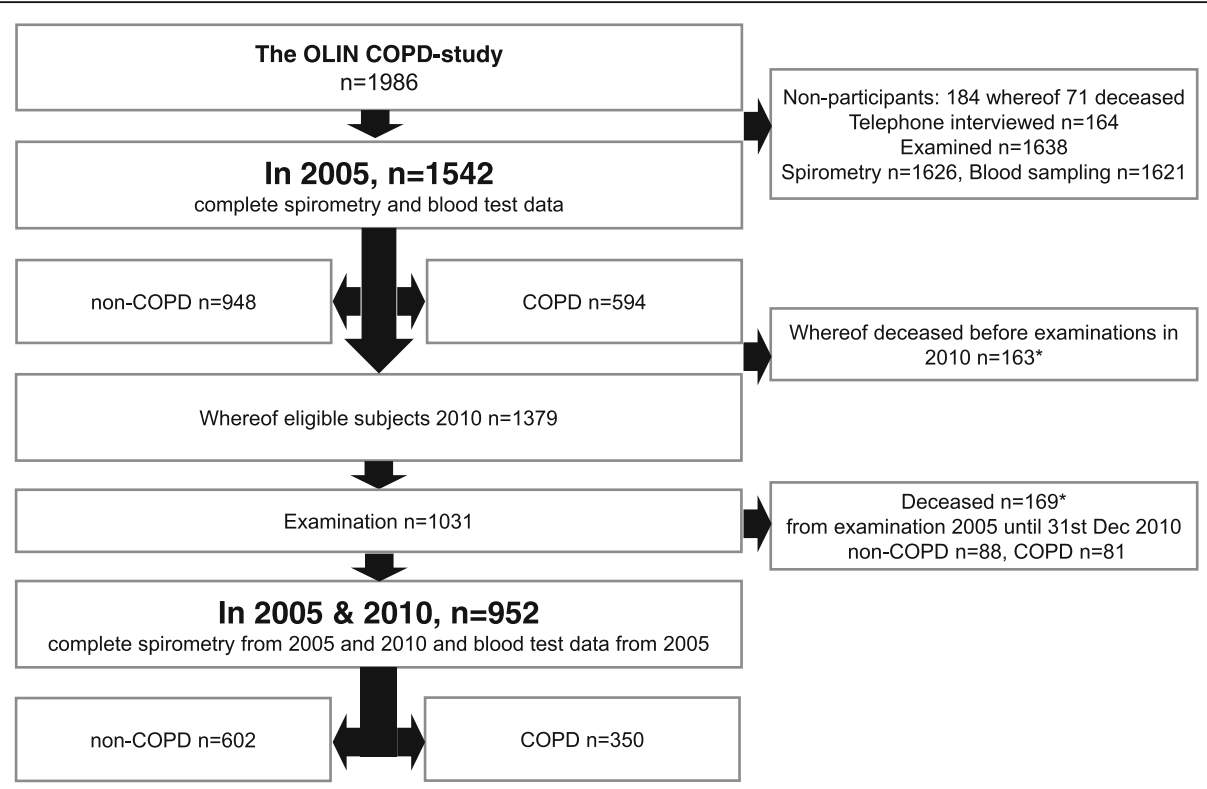

Fig. 1 Flowchart of the study population

median and interquartile range (IQR). Mortality risk is expressed as hazard ratio (HR) and analysed in a Coxregression model. The IBM SPSS Statistics for Macintosh, version 23 (IBM Corp., Armonk, N.Y., USA) was used for all analyses and $P$-values $<0.05$ were considered significant.

\section{Results}

Basic characteristics and biomarker serum concentrations among participants in 2005

The study population from 2005 included in total 1542 subjects, whereof 594 with COPD (Table 1). The distribution by GOLD grade among those with COPD was $64 \%$ GOLD 1, 32\% GOLD 2 and 4\% GOLD 3-4. The serum concentration of MMP-9 (median, interquartile range,
(IQR)) was significantly lower in non-COPD than COPD; 505 (364-606) vs. 535 (315-653) ng/ml, $p=0.017$. Contrastingly, the concentration of TIMP-1 and the MMP-9/ TIMP-1-ratio were similar in non-COPD and COPD; 316 $(220-490)$ vs. $304(227-430) \mathrm{ng} / \mathrm{ml}, p=0.252$ and $1.36(0$. $85-2.09)$ vs. 1.50 (0.83-2.32), $p=0.168$. Basic characteristics are previously published in the referred publication from the same study [8].

\section{Annual lung function decline}

The cohort generated 5174 person-years and was followed for a median (IQR) of 5.53 (5.21-5.64) years. In total, 952 subjects, whereof 424 (45\%) women, participated in the clinical examinations including spirometry in both 2005 and 2010. The median (IQR) annual decline in $\mathrm{FEV}_{1}$ was

Table 1 Study population, basic characteristics in 2005, comparing non-COPD and COPD

\begin{tabular}{|c|c|c|c|}
\hline & $\begin{array}{l}\text { Non-COPD } \\
n=948\end{array}$ & $\begin{array}{l}\text { COPD } \\
n=594\end{array}$ & $P$ \\
\hline Female, n (\%) & $447(47)$ & $248(42)$ & 0.038 \\
\hline Age (years), median (IQR) & $67(55-71)$ & $69(57-71)$ & 0.015 \\
\hline BMI $\left(\mathrm{kg} / \mathrm{m}^{2}\right)$, median (IQR) & $27(24-30)$ & $26(24-29)$ & $<0.001$ \\
\hline Non-smoker, n (\%) & $443(47)$ & $149(25)$ & $<0.001$ \\
\hline Ex-smoker, n (\%) & $384(41)$ & $247(42)$ & 0.676 \\
\hline Current smoker, n (\%) & $120(13)$ & $197(33)$ & $<0.001$ \\
\hline Pack years, median (IQR) & $0.8(0-12)$ & $14(0-27)$ & $<0.001$ \\
\hline $\mathrm{FEV}_{1} \%$ predicted, median (IQR) & $1.03(0.93-1.13)$ & $0.85(0.73-0.96)$ & $<0.001$ \\
\hline Productive cough, n (\%) & $212(22)$ & $238(40)$ & $<0.001$ \\
\hline Heart disease, n (\%) & $149(16)$ & $111(19)$ & 1.000 \\
\hline
\end{tabular}

IQR Inter quartile range. Significant $p$-values in bold 
similar in COPD and non-COPD, $-40(-64--22)$ and $46(-68--16) \mathrm{ml} /$ year respectively, $(p=0.428)$. The annual decline in percent-units of $\mathrm{FEV}_{1}$ percent predicted was less in non-COPD than COPD; $-0.21(-1.10-0.51)$ vs. $-0.54(-1.43-0.50), p=0.020$.

\section{Relation between biomarker values and lung function decline}

The correlation between biomarker levels and annual lung function decline, when using change in $\mathrm{ml} \mathrm{FEV}_{1}$ as well as change in units of $\mathrm{FEV}_{1}$ percent predicted value, had a similar pattern in non-COPD and COPD. Though it was significant for MMP-9 and MMP-9/TIMP-1-ratio only in non-COPD (Table 2).

A non-response analysis was carried out, comparing biomarker values in 2005 between subjects participating and not participating in examination with spirometry in 2010 (deceased were excluded from the analyses) (Fig. 1). The analysis showed a higher level of MMP-9 and an increased MMP-9/TIMP-1 ratio along with a decreased TIMP-1 concentration in 2005 when comparing non-participants and participants at examination in 2010. This was evident in both non-COPD and COPD (Additional file 1: Table S1).

\section{Biomarkers, mortality and risk factors for death}

In total, 169 individuals died during the observation time. The cumulative mortality was lower in non-COPD, $10 \%(n=88)$, than in COPD, $16 \%(n=81), p=0.008$. In both non-COPD and COPD subjects, serum MMP-9 as well as MMP-9/TIMP-1 ratio in 2005 were higher among those who died during the observation time compared to among those who were alive and eligible for follow-up in 2010 (Table 3). Both MMP-9 level and MMP-9/TIMP-1 ratio were higher among deceased subjects with COPD than among deceased non-COPD individuals (Table 4).

Univariate analyses revealed that increasing age, male sex and heart disease as well as increasing levels of MMP-

Table 2 Linear regression analysis of biomarker levels 2005 in relation to lung function decline, in non-COPD and COPD respectively

\begin{tabular}{|c|c|c|c|c|}
\hline \multirow{2}{*}{$\begin{array}{l}\text { Change in: } \\
\mathrm{ml} \mathrm{FEV}_{1}\end{array}$} & \multicolumn{2}{|c|}{ non-COPD } & \multicolumn{2}{|l|}{ COPD } \\
\hline & Beta & $P$ & Beta & $P$ \\
\hline MMP-9 & -0.098 & 0.016 & -0.063 & 0.240 \\
\hline TIMP-1 & 0.100 & 0.014 & 0.025 & 0.648 \\
\hline MMP-9/TIMP-1 ratio & -0.128 & 0.002 & -0.072 & 0.183 \\
\hline \multicolumn{5}{|c|}{ units of $\mathrm{FEV}_{1}$ percent predicted value } \\
\hline MMP-9 & -0.117 & 0.004 & -0.091 & 0.089 \\
\hline TIMP-1 & 0.056 & 0.169 & 0.009 & 0.864 \\
\hline MMP-9/TIMP-1-ratio & -0.109 & 0.007 & -0.086 & 0.110 \\
\hline
\end{tabular}

Significant values in bold
9 and MMP-9/TIMP-1 ratio were associated with an increased risk for death, expressed as Hazard Ratio (HR, 95\% CI). This was the case in both non-COPD and COPD, while smoking status was a significant risk factor for death only among non-COPD subjects. Productive cough and lower $\mathrm{FEV}_{1}$ were each associated with a higher risk for death in COPD (Additional file 1: Table S2).

In a multivariate model, male sex, age, ex- and current smoking, heart disease, decreased TIMP-1 and increased MMP-9/TIMP-1 ratio were significantly associated with increased risk for death in non-COPD subjects, while age, current smoking as well as increased MMP-9 and MMP-9/TIMP-1 ratio were associated with increased risk for death among those with COPD (Table 5). These results remained significant also when adjusted for lung function assessed as $\mathrm{FEV}_{1} \%$ predicted (Additional file 1: Table S3) and productive cough respectively (Additional file 1: Table S4). When smoking status was replaced by pack-years, MMP-9/TIMP-1 ratio was no longer significant in non-COPD but remained significant in COPD and so did MMP-9 (Additional file 1: Table S5).

\section{Discussion}

In this population-based study, subjects with and without COPD showed a different risk factor pattern when evaluating biomarkers in relation to prognosis, assessed as mortality. In non-COPD, male sex, burden of smoking, heart disease and MMP-9/TIMP-1 ratio increased the risk for death, and serum concentration of TIMP-1 had a protective effect. Meanwhile in COPD, age, current smoking and increased serum concentration of MMP-9 and MMP-9/TIMP-1 ratio increased the risk for death. These findings bring additional verification of MMP-9's impact on COPD, previously explored in epidemiological, [11, 20-23] as well as recent genetic studies [24] This supports earlier findings of MMP-9's relation to mortality in other groups of subjects $[25,26]$. Though the present results imply that protease-antiprotease imbalance has a prognostic impact both among subjects with and without COPD, their risk factor patterns did differ. In COPD, the biomarker pattern indicates that an increased proteolytic activity is associated with an increased risk for death and the significance of these biomarkers' importance for the prognosis in COPD merits further evaluation.

Based on the results in a selected population of COPD-patients [10], we expected to find a correlation between the selected biomarkers and lung function decline in COPD, but this was not the case. Still, when comparing the 2005-biomarkers among those who did and those who did not attend in 2010, a greater protease-anti-protease imbalance was indicated among non-participants. Likewise, those who died during follow-up had higher MMP-9 and MMP-9/TIMP-1 ratio 
Table 3 Comparing serum biomarker levels 2005 among survivors and subjects deceased during the observation time, in nonCOPD and COPD respectively

\begin{tabular}{|c|c|c|c|c|c|c|}
\hline \multirow[t]{2}{*}{ Biomarkers } & \multicolumn{2}{|l|}{ non-COPD } & \multirow[t]{2}{*}{$P$} & \multicolumn{2}{|l|}{ COPD } & \multirow[t]{2}{*}{$P$} \\
\hline & $\begin{array}{l}\text { Participating } \\
n=860\end{array}$ & $\begin{array}{l}\text { Deceased } \\
n=88\end{array}$ & & $\begin{array}{l}\text { Participating } \\
n=513\end{array}$ & $\begin{array}{l}\text { Deceased } \\
n=81\end{array}$ & \\
\hline & Median (IQR) & Median (IQR) & & Median (IQR) & Median (IQR) & \\
\hline MMP-9 (ng/ml) & $501(346-605)$ & 535 (428-628) & 0.026 & $514(210-641)$ & $607(493-681)$ & $<0.001$ \\
\hline TIMP-1 (ng/ml) & $311(224-521)$ & $327(250-381)$ & 0.670 & $300(222-479)$ & $311(260-366)$ & 0.839 \\
\hline MMP-9/TIMP-1 ratio & $1.34(0.81-2.09)$ & $1.71(1.19-2.16)$ & 0.001 & $1.38(0.76-2.29)$ & $1.86(1.52-2.34)$ & $<0.001$ \\
\hline
\end{tabular}

$I Q R$ Inter quartile range. Significant $p$-values in bold

in 2005 than those who lived and participated in followup, and the levels were higher in COPD than nonCOPD. Notwithstanding the association between biomarkers and lung function decline in non-COPD, this could not be proven in COPD. However, we assume that there is an influence also among those with COPD that cannot be demonstrated here, due to the loss of follow up of those with the highest serum biomarker levels. The findings imply a healthy survivor effect, which could offer an explanation to the somewhat unexpected absence of a correlation between biomarkers and lung function decline in COPD, when assessed over a fiveyear period. The lower mortality and lower biomarker levels associated with mortality in non-COPD than COPD provides a different basis for evaluating decline in lung function in relation to the biomarkers and may contribute to the observed significant relationship in non-COPD.

To the best of our knowledge, this is the first time these biomarkers have been evaluated in relation to prognosis and assessed as risk factors for death in a population-based COPD study. In both groups, MMP9 levels and MMP-9/TIMP-1 ratio in 2005 were higher among those who died compared to those who survived. Furthermore, among those with COPD, these biomarkers were associated with an increased risk for death, also after adjustment for confounders, and independent of disease severity, assessed as $\mathrm{FEV}_{1} \%$ of predicted. This suggests that markers of increased proteolytic imbalance may be an important

Table 4 Comparing serum biomarker levels 2005 between deceased in non-COPD and COPD during the observation time

\begin{tabular}{llll}
\hline Biomarkers & $\begin{array}{l}\text { non-COPD } \\
\text { Deceased } \\
n=88\end{array}$ & $\begin{array}{l}\text { COPD } \\
\text { Deceased } \\
n=81\end{array}$ & $P$ \\
\hline Median (IQR) & Median (IQR) & \\
MMP-9 $(\mathrm{ng} / \mathrm{ml})$ & $534.5(427.5-628)$ & $607(493-681)$ & $\mathbf{0 . 0 0 1}$ \\
TIMP-1 $(\mathrm{ng} / \mathrm{ml})$ & $327(250-381)$ & $311(260-366)$ & 0.488 \\
MMP-9/TIMP-1-ratio & $1.71(1.19-2.16)$ & $1.86(1.52-2.34)$ & $\mathbf{0 . 0 2 0}$ \\
\hline
\end{tabular}

IQR Inter quartile range. Significant $p$-values in bold disease mechanism in COPD and an issue that deserves further evaluation. In non-COPD subjects, other risk factors appear more consequential as risk factors for death, and TIMP-1 had a protective effect.

Lung function decline in COPD is proposed for evaluation across several years, as $\mathrm{FEV}_{1}$ values may naturally fluctuate between different examinations carried out at shorter time intervals [27]. Similar to the last point, the progression of COPD has been found to be heterogeneous and thus a long interval of follow up may be more indicative of lung function decline in a population than a shorter interval [28]. In the current study, decline in lung function was assessed over a period of approximately five years, which can be considered satisfactory.

Phenotyping studies have explained the heterogeneity in COPD and might represent an opportunity to enhance diagnosis, predict outcomes and personalize treatments in patients. Suggested COPD phenotypes are based on clinical parameters such as; emphysema severity measured by $\mathrm{CT}$, spirometry, nutritional status, exercise capacity

Table 5 Risk for death expressed as HR (95\% CI), analyses stratified for non-COPD and COPD in a Cox regression model adjusting for sex, age, smoking status and heart disease

\begin{tabular}{|c|c|c|}
\hline & $\begin{array}{l}\text { Non-COPD } \\
n=948\end{array}$ & $\begin{array}{l}\text { COPD } \\
n=594\end{array}$ \\
\hline & HR $(95 \% \mathrm{Cl})$ & HR $(95 \% \mathrm{Cl})$ \\
\hline Female & 1 & 1 \\
\hline Male & 1.700 (1.067-2.708) & $1.538(0.938-2.523)$ \\
\hline $\mathrm{Age}^{\mathrm{a}}$ & 1.105 (1.078-1.134) & $1.112(1.083-1.142)$ \\
\hline Non-smoker & 1 & 1 \\
\hline Ex-smoker & $\mathbf{2 . 1 8 2}(1.318-3.611)$ & $1.296(0.709-2.370)$ \\
\hline Current smoker & $4.917(2.357-10.257)$ & $\mathbf{2 . 4 2 9}(1.296-4.552)$ \\
\hline No heart disease & 1 & 1 \\
\hline Heart disease & $2.443(1.574-3.792)$ & $1.361(0.843-2.197)$ \\
\hline MMP- $9^{a, b}$ & $1.001(1.000-1.003)$ & $1.003(1.002-1.004)$ \\
\hline TIMP-1 $1^{a, b}$ & $0.997(0.996-0.999)$ & $0.998(0.997-1.000)$ \\
\hline MMP-9/TIMP-1-ratio ${ }^{a, b}$ & $1.099(1.014-1.190)$ & $1.299(1.086-1.555)$ \\
\hline
\end{tabular}


and exacerbation frequency [29, 30]. Presumably, one parameter could be associated to many phenotypes, and there is probably an overlap between phenotypes in the population. Based on the knowledge of AATD and COPD [4], it seems appropriate to associate markers of increased proteolytic imbalance to greater parenchymal degradation and emphysema development. It is unclear to what extent various parameters and phenotypes define the complex syndrome of COPD, as presented in the population. However, proteolytic imbalance appears to be a factor that is significant on a population level $[22,31]$, and the results generate hypotheses for future studies of COPD phenotypes.

The distribution of COPD severity in our cohort is comparable to what has been reported from other population-based studies, including individuals with predominantly mild- to moderate COPD [20, 32, 33]. COPD was based on post-bronchodilator spirometry, and both internal and external validity are considered good. In a population-based study, the results will not be affected by the under-diagnosis of COPD, allowing a discussion of generalizability to COPD in the general population.

Limitations of this study that merit further discussion are firstly that the analysis of MMP-9 and TIMP-1 includes both total and pro-enzyme levels. Secondly, serum MMP-9 levels may not reflect overall MMP-9 airway activity, since enzyme levels do not directly reflect enzyme activity. Further, in the present study, all samples have been collected during field studies and stored at $-20{ }^{\circ} \mathrm{C}$. Thus, a decrease in MMP-9 levels across time, cannot be excluded [4]. The possible effects of storage are expected to affect all samples in an equivalent manner, as they were all collected within the same year, but the geometric decrease in measurable enzymes should be the same for all samples. The measured absolute values may be influenced by storage, but not likely the results, regarding the observed correlations. Furthermore, prognosis was assessed as all-cause mortality and the association between these biomarkers and specific cause of death would be of interest. However, unfortunately, data on cause-specific mortality were not available when this manuscript was completed.

\section{Conclusions}

In this population-based study, we could not demonstrate the expected association between the measured biomarkers and lung function decline among subjects with COPD. This result may, after analyses of nonparticipation, be explained by a healthy survivor effect. Increased MMP-9 serum levels and MMP-9/TIMP-1 ratio, indicating increased proteolytic imbalance, were associated with mortality in both subjects with and without
COPD. Among subjects with COPD, both these biomarkers were associated with an increased risk for death also when adjusted for common confounders. We propose that the prognostic value of systemic markers of increased proteolytic imbalance can be translated to a population level by this study, which includes predominantly mild and moderate COPD. Future longitudinal studies are important for the further understanding of MMP-9 and TIMP-1 in relation to the pathogenesis and prognosis of different COPD phenotypes.

\section{Additional file}

Additional file 1: Table S1. Serum biomarkers in 2005, comparing subjects participating respectively alive but not participating in examination 2010. Table S2. Univariate Cox regression analyses of risk for death expressed as HR $(95 \% \mathrm{Cl})$, analyses stratified for non-COPD and COPD. Table S3. Risk for death expressed as HR $(95 \% \mathrm{Cl})$, analyses stratified for non-COPD and COPD in a Cox regression model adjusting for sex, age, smoking-status, heart disease and $\mathrm{FEV}_{1} \%$. Table S4. Risk for death expressed as $\mathrm{HR}(95 \% \mathrm{Cl})$, analyses for COPD in a Cox regression model adjusting for sex, age, smoking-status, heart disease and productive cough. Table S5. Risk for death expressed as HR $(95 \% \mathrm{Cl})$, analyses stratified for non-COPD and COPD in a Cox regression model adjusting for sex, age, pack-years and heart disease. (DOCX $23 \mathrm{~kb}$ )

\section{Abbreviation}

AATD: Alpha-1 Antitrypsin Deficiency; COPD: Chronic Obstructive Pulmonary Disease; ELISA: Enzyme-Linked Immunosorbent Assay; FEV ${ }_{1}$ : Forced Expiratory Volume in one second; FVC: Forced Vital Capacity; GOLD: Global Initiative for Obstructive Lung Disease; HR: Hazard Ratio; IQR: Interquartile Range; MMP9: Matrix Metalloproteinase-9; OLIN: Obstructive Lung disease In Northern Sweden; SVC: Slow Vital Capacity; TIMP-1: Tissue Inhibitor of Metalloproteinases-1; VC: Vital Capacity

\section{Acknowledgements}

The authors acknowledge Bo Lundbäck, the founder of the OLIN-studies and initiator of the OLIN COPD-study. The authors thank Helena Backman and Hans Stenberg for statistical support, and Ann-Christin Jonsson, Sigrid Sundberg and Linnea Hedman for data collection.

\section{Funding}

The Swedish Heart-Lung Foundation, Umeå University, King Gustaf V's and Queen Victoria's Freemason Foundation, Visare Norr Fund/Northern County Council's Regional Federation, Norrbotten and Västerbotten county councils funded the study.

\section{Availability of data and materials}

Data and materials has not been made public in any online repository. Questionnaires and consent forms are stored locally as paper. Datasets are stored on a select few local computers.

\section{Authors' contributions}

RL carried out the statistical analyses, drafting and writing of the manuscript. ER participated in the design of the study and in the writing of the manuscript. JP carried out the immunoassays and wrote part of the manuscript. AFB participated in writing the manuscript. AB participated in drafting and writing the manuscript. AL participated in the design of the study, drafting and writing the manuscript. All authors read and approved the final manuscript.

\section{Ethics approval and consent to participate}

The Regional Ethics Committee at Umeå University approved the study, which was carried out according to the declaration of Helsinki. All participants provided written informed consent before the performance of any study-related assessments. 


\section{Competing interests}

The authors declare that they have no competing interests.

\section{Publisher's Note}

Springer Nature remains neutral with regard to jurisdictional claims in published maps and institutional affiliations.

\section{Author details}

${ }^{1}$ Department of Public Health and Clinical Medicine, Division of Medicine, Umeå University, SE-90187 Umeå, Sweden. ${ }^{2}$ Department of Public Health and Clinical Medicine, the OLIN unit, Division of Occupational and Environmental Medicine, Umeå University, SE-90187 Umeå, Sweden.

\section{Received: 18 December 2017 Accepted: 4 April 2018}

Published online: 12 April 2018

\section{References}

1. Carolan BJ, Sutherland ER. Clinical phenotypes of chronic obstructive pulmonary disease and asthma: recent advances. J Allergy Clin Immunol. 2013;131:627-34

2. López-Campos JL, Tan W, Soriano JB. Global burden of COPD. Respirology. 2015;21:14-23

3. Bernd L, Joan BS, Michael S, Bernhard K, Lowie EV, Louisa G, Peter B, Marc M Francisco G-R, Kaveh A, Julio A, Ana MM, Rogelio P-P, Maria M de O, Carlos AT-D, Andres C, Mauricio G-G, Sonia B. Determinants of Underdiagnosis of COPD in national and international surveys. Chest. 2015;148:971-85.

4. Wanner A, New Lessons COPD-. From a 1-antitrypsin deficiency? Chest 2009;135:1342

5. Brajer B, Batura-Gabryel H, Nowicka A, Kuznar-Kaminska B, Szczepanik A Concentration of matrix metalloproteinase-9 in serum of patients with chronic obstructive pulmonary disease and a degree of airway obstruction and disease progression. J Physiol Pharmacol. 2008:59(Suppl 6):145-52.

6. Beeh KM, Beier J, Kornmann O, Buhl R. Sputum matrix metalloproteinase-9, tissue inhibitor of metalloprotinease-1, and their molar ratio in patients with chronic obstructive pulmonary disease, idiopathic pulmonary fibrosis and healthy subjects. Respir Med. 2003:97:634-9.

7. Higashimoto $Y$, Yamagata $Y$, Iwata T, Okada M, Ishiguchi T, Sato H, Masuda $\mathrm{M}$, Itoh $\mathrm{H}$. Increased serum concentrations of tissue inhibitor of metalloproteinase-1 in COPD patients. Eur Respir J. 2005;25:885-90.

8. Linder R, Rönmark E, Pourazar J, Behndig A, Blomberg A, Lindberg A. Serum metalloproteinase-9 is related to COPD severity and symptoms - crosssectional data from a population based cohort-study. Respir Res. 2015;16:347.

9. Cataldo D, Munaut C, Noël A, Frankenne F, Bartsch P, Foidart JM, Louis R. MMP-2- and MMP-9-linked Gelatinolytic activity in the sputum from patients with asthma and chronic obstructive pulmonary disease. Int Arch Allergy Immunol. 2000;123:259-67.

10. Higashimoto Y, Iwata T, Okada M, Satoh H, Fukuda K, Tohda Y. Serum biomarkers as predictors of lung function decline in chronic obstructive pulmonary disease. Respir Med. 2009;103:1231-8.

11. Omachi TA, Eisner MD, Rames A, Markovtsova L, Blanc PD. Matrix metalloproteinase-9 predicts pulmonary status declines in a1-antitrypsin deficiency. Respir Res. 2011;12:441.

12. Lindberg A, Lundbäck B. The obstructive lung disease in northern Sweden chronic obstructive pulmonary disease study: design, the first year participation and mortality. Clin Respir J. 2008;2:64-71.

13. Lundbäck B, Stjernberg N, Nyström L, Forsberg B, Lindström $M$, Lundbäck K, Jönsson $E$, Rosenhall $L$. Epidemiology of respiratory symptoms, lung function and important determinants. Tuber Lung Dis. 1994:75:116-26.

14. Pallasaho P, Lundbäck B, Läspä SL, Jönsson E, Kotaniemi J, Sovijärvi ARA, Laitinen LA. Increasing prevalence of asthma but not of chronic bronchitis in Finland? Report from the FinEsS-Helsinki study. Respir Med. 1999:93:798-809.

15. Lundbäck B, Eriksson B, Lindberg A, Ekerljung L, Muellerova H, Larsson L-G Rönmark E. A 20-year follow-up of a population study-based COPD cohortreport from the obstructive lung disease in northern Sweden studies. COPD: J Chron Obstruct Pulmon Dis. 2009;6:263-71.

16. ATS board of directors. Standardization of Spirometry, 1994 Update. American Thoracic Society. Am J Respir Crit Care Med. 152:1107-36.

17. GOLD 2017 Global strategy for the diagnosis, Management and Prevention of COPD - Global Initiative for Chronic Obstructive Lung Disease - GOLD.
18. Backman $H$, Lindberg A, Sovijärvi A, Larsson K, Lundbäck B, Rönmark E. Evaluation of the global lung function initiative 2012 reference values for spirometry in a Swedish population sample. BMC Pulm Med. 2015;15:26.

19. Lindberg A, Larsson L-G, Rönmark E, Jonsson A-C, Larsson K, Lundbäck B. Decline in FEV 1in relation to incident chronic obstructive pulmonary disease in a cohort with respiratory symptoms. COPD: J Chron Obstruct Pulmon Dis. 2009:4:5-13.

20. Olafsdóttir IS, Janson C, Lind L, Hulthe J, Gunnbjörnsdóttir M, Sundström J. Serum levels of matrix metalloproteinase-9, tissue inhibitors of metalloproteinase-1 and their ratio are associated with impaired lung function in the elderly: a population-based study. Respirology. 2010;15:530-5.

21. Montaño M, Sansores RH, Becerril C, Cisneros J, González-Avila G, Sommer B, Ochoa L, Herrera I, Ramírez-Venegas A, Ramos C. FEV1 inversely correlates with metalloproteinases 1, 7,9 and CRP in COPD by biomass smoke exposure. Respir Res. 2014;15:74.

22. Sand JMB, Leeming DJ, Byrjalsen I, Bihlet AR, Lange P, Tal-Singer R, Miller BE, Karsdal MA, Vestbo J. High levels of biomarkers of collagen remodeling are associated with increased mortality in COPD - results from the ECLIPSE study. Respir Res. 2016;17:2095

23. Górska K, Paplińska-Goryca M, Nejman-Gryz P, Goryca K, Krenke R. Eosinophilic and neutrophilic airway inflammation in the phenotyping of mild-to-moderate asthma and chronic obstructive pulmonary disease. COPD: J Chron Obstruct Pulmon Dis. 2017;14:181-9.

24. Jiang S, Yang ZH, Chen YY, He Z, Zhou Y, Gao Y, Zhang Q, Tan MQ. MMP-9 genetic polymorphism may confer susceptibility to COPD. Genet Mol Res. 2016;15

25. Lorente L, Martín MM, Solé-Violán J, Blanquer J, Labarta L, Díaz C, Borreguero-León JM, Orbe J, Rodríguez JA, Jiménez A, Páramo JA. Association of sepsis-related mortality with early increase of TIMP-1/MMP-9 ratio. PLoS One. 2014:9:e94318.

26. Hansson J, Vasan RS, Ärnlöv J, Ingelsson E, Lind L, Larsson A, Michaëlsson K, Sundström J. Biomarkers of extracellular matrix metabolism (MMP-9 and TIMP-1) and risk of stroke, myocardial infarction, and cause-specific mortality: cohort study. PLoS One. 2011;6:e16185.

27. Vestbo J, Lange P. Natural history of COPD: focusing on change in FEV 1. Respirology. 2015;21:34-43.

28. Casanova C, de Torres JP, Aguirre-Jaíme A, Pinto-Plata V, Marin JM, Cordoba E, Baz R, Cote C, Celli BR. The progression of chronic obstructive pulmonary disease is heterogeneous. Am J Respir Crit Care Med. 2011;184:1015-21.

29. Han MK, Agusti A, Calverley PM, Celli BR, Criner G, Curtis JL, Fabbri LM, Goldin JG, Jones PW, Macnee W, Make BJ, Rabe KF, Rennard SI, Sciurba FC, Silverman EK, Vestbo J, Washko GR, Wouters EFM, Martinez FJ. Chronic obstructive pulmonary disease phenotypes. Am J Respir Crit Care Med. 2010:182:598-604

30. Garcia-Aymerich J, Gomez FP, Benet M, Farrero E, Basagana X, Gayete A, Pare C, Freixa X, Ferrer J, Ferrer A, Roca J, Galdiz JB, Sauleda J, Monso E, Gea J, Barbera JA, Agusti A, Anto JM, Group OBOTP-CS. Identification and prospective validation of clinically relevant chronic obstructive pulmonary disease (COPD) subtypes. Thorax. 2010;66:430-7.

31. Ostridge K, Williams N, Kim V, Harden S, Bourne S, Coombs NA, Elkington PT, Estepar RSJ, Washko G, Staples KJ, Wilkinson TMA. Distinct emphysema subtypes defined by quantitative $C T$ analysis are associated with specific pulmonary matrix metalloproteinases. Respir Res. 2016;17:709.

32. Miravitlles M, Soriano JB, García-Río F, Muñoz L, Duran-Tauleria E, Sanchez G, Sobradillo $V$, Ancochea J. Prevalence of COPD in Spain: impact of undiagnosed COPD on quality of life and daily life activities. Thorax. 2009; 64:863-8.

33. Bourbeau J, Tan WC, Benedetti A, Aaron SD, Chapman KR, Coxson HO, Cowie R, Fitzgerald M, Goldstein R, Hernandez P, Leipsic J, Maltais F, Marciniuk D, O'Donnell D, Sin DD, For the Cancold study group. Canadian cohort obstructive lung disease (CanCOLD): fulfilling the need for longitudinal observational studiles in COPD. COPD: J Chron Obstruct Pulmon Dis. 2014;11:125-32. 